\title{
Pregnant With Myocardial Infarction, How Should I Manage?
}

\author{
Emin Uysal ${ }^{\mathrm{a}, \mathrm{c}}$, Suleyman Solak ${ }^{\mathrm{a}}$, Sakir Omur Hincal ${ }^{\mathrm{a}}$, \\ Sinan Varol ${ }^{\mathrm{b}}$
}

\begin{abstract}
Myocardial infarction (MI) during pregnancy is rare but has important risks for the mother and the fetus. Its prevalence is $1 / 10,000-30,000$. A 38-year-old woman at the 37 th gestation week was admitted to the emergency department with the complaint of chest pain. She had undergone mitral valve replacement previously. Her electrocardiograph and clinic are in line with ST elevation inferior MI. A thrombus was identified by angiography at posterolateral of circumflex artery. The patient was followed up with medical treatment, and she had normal birth without any complications. The mother and the baby were discharged from hospital to their home after the follow-up period. In conclusion, emergency intervention should be considered for the pregnant women with MI that can be rare but fatal for the mother and the baby.
\end{abstract}

Keywords: Pregnancy; Myocardial infarction; Emergency

\section{Introduction}

Myocardial infarction (MI) during pregnancy is rare but important since its mortality is $37-50 \%$ [1]. Its prevalence is $1 / 10,000-30,000$. Approximately $30 \%$ of the cases had normal coronary arteries $[2,3]$. This condition is associated with acute coronary thrombosis induced by hypercoagulability [3]. Our aim in this case is that acute myocardial infarction (AMI) management should be considered for the pregnant women who were admitted to emergency department with the complaints of chest pain and diagnosed as ST elevation myocardial infarction (STEMI).

Manuscript accepted for publication April 24, 2017

aDepartment of Emergency Medicine, Bagcilar Research and Training Hospital, Bagcilar Egitim ve Arastirma Hastanesi Acil Tip Klinigi, Bagcilar, Istanbul 34200, Turkey

bepartment of Cardiology, Bagcilar Research and Training Hospital, Bagcilar Egitim ve Arastirma Hastanesi Kardiyoloji Klinigi, Bagcilar, Istanbul 34200, Turkey

${ }^{\mathrm{c} C}$ Corresponding Author: Emin Uysal, Department of Emergency Medicine, Bagcilar Research and Training Hospital, Bagcilar Egitim ve Arastirma Hastanesi Acil Tip Klinigi, Bagcilar, Istanbul 34200, Turkey.

Email: dreminuysal@hotmail.com

doi: https://doi.org/10.14740/jmc2827w

\section{Case Report}

A 38-year-old woman at the 37th gestation week of her second child was admitted to the emergency department with the complaint of chest pain. Her chest pain has begun about $1 \mathrm{~h}$ before the admission. The patient had retrosternal, not widespread pressure style chest pain. She had not a history of a coronary artery disease. She had undergone mitral valve replacement 4 years ago. She had been using $5 \mathrm{mg}$ /day warfarin tablets perorally after the replacement. The history revealed that she discontinued warfarin tablets, and started no low-molecular weight heparin when she became pregnant. No feature was found in her family history. She was conscious and her general condition was good in the emergency department. Arterial blood pressure was $90 / 60 \mathrm{~mm} \mathrm{Hg}$, pulse rate was 83 beats/ min, respiratory rate was $18 / \mathrm{min}$ and $\mathrm{SpO}_{2}$ was $92 \%$. Heart was rhythmic and a metallic heart sound was heard. An incision scar due to valve replacement was present on the front side of the thorax. Uterus was optimal for the gestation week. The other system examinations were normal. In electrocardiography, there was sinus rhythm, ST segment elevation $>2$ $\mathrm{mm}$ on DII, DIII and aVF derivations, $0.5-1 \mathrm{~mm}$ elevation on V5, V6 and reciprocal change of ST segment depression on aVL (Fig. 1). Blood samples were taken. Cardiology consultation was done and $100 \mathrm{mg}$ acetylsalicylic acid was given perorally and 5,000 units heparin was given intravenously in the emergency department. She was referred to coronary angiography unit and coronary artery angiography was performed with the abdominal protection by lead vest. Coronary angiography identified a total distal obstruction in the posterolateral (PL) branch of right circumflex artery (RCA) (Fig. 2). The obstruction was decided to be followed up medically without a stent or percutaneous transluminal coronary angioplasty. During angiography, amniotic pouch ruptured spontaneously and after the cardiac stabilization she was consulted with an obstetrician. Then the patient was taken to the delivery room. Oxytocin infusion was started and $600 \mathrm{mg}$ misoprostol was given rectally. Normal vaginal delivery with cephalic presentation was performed. No retro and preplacental hemorrhage was observed. No complication was observed. The baby was referred to neonatal unit, and the mother was referred to coronary intense care unit. Heparin 100 unit/h infusion was started to the patient at the first day, and $100 \mathrm{mg}$ acetylsalicylic acid once a day, $50 \mathrm{mg}$ metoprolol once a day, $40 \mathrm{mg}$ atorvastatin once a day, $40 \mathrm{mg}$ pantoprazole once a day were administrated. At the second day, heparin infusion was continued, and clopidogrel and warfarin were administrated. At the fifth day, she 


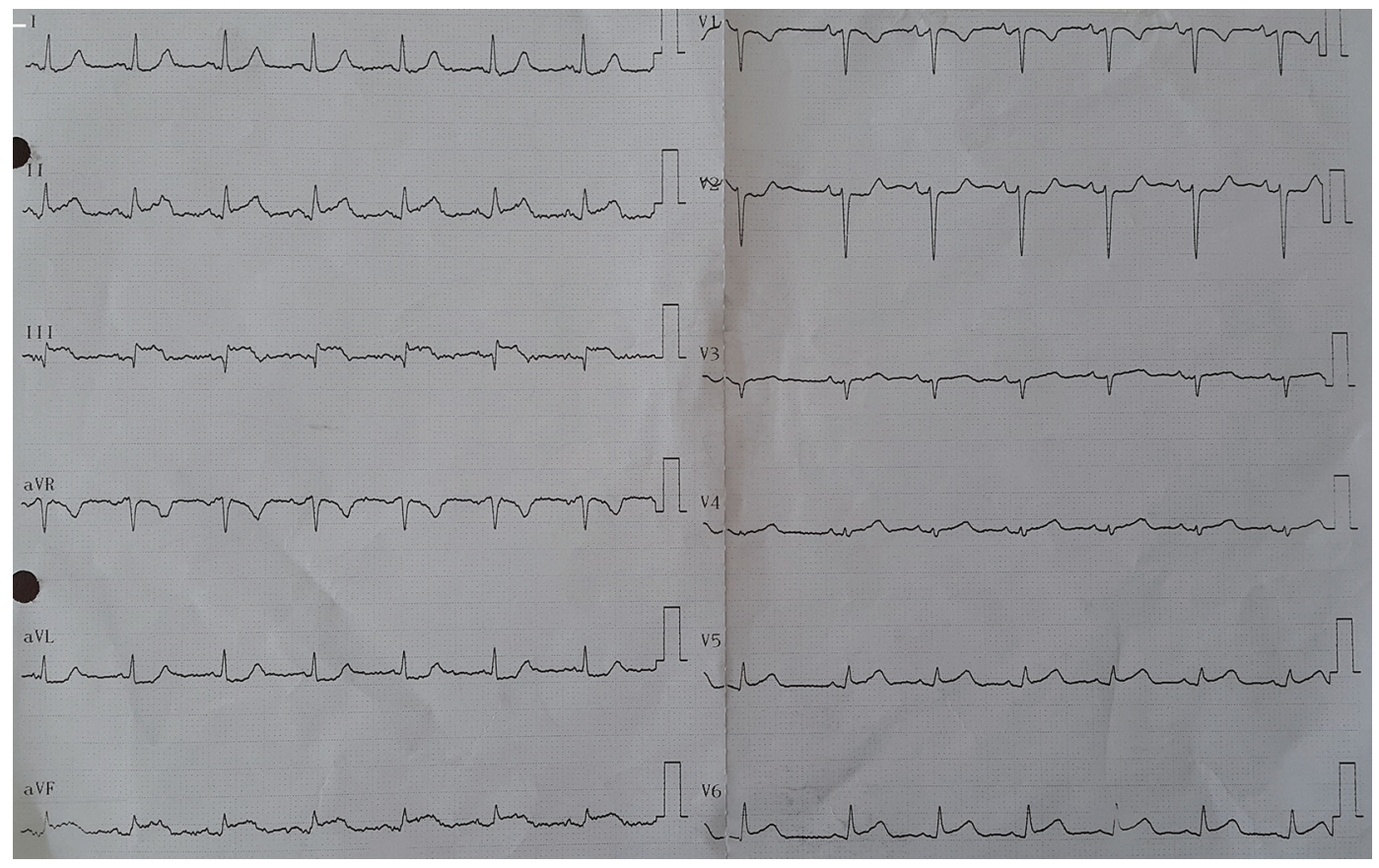

Figure 1. Electrocardiography of patient.

was referred to cardiology department from the intensive care unit. During the follow-up period, cardiac enzyme levels increased gradually and then decreased. Troponin $\mathrm{T}$ value was $0.023 \mathrm{ng} / \mathrm{mL}(0-0.014)$ in the blood sample at admission, and the peak value was $0.149 \mathrm{ng} / \mathrm{mL}$. Serum creatine kinase (CK) and CK-MB values were $49 \mathrm{U} / \mathrm{L}(20$ - 170) and $34 \mathrm{U} / \mathrm{L}(1$ 25), respectively in the blood sample during admission, and the peak values were 197 and 36 U/L. Fasting blood sugar, blood urea nitrogen (BUN), creatinine, especially INR, aPTT

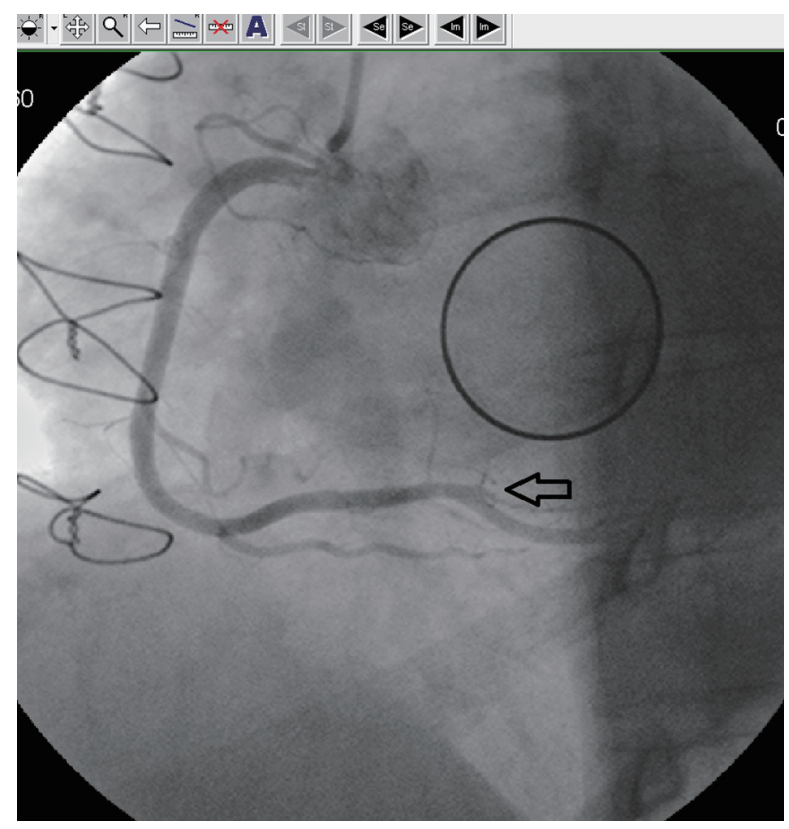

Figure 2. Coronary angiography of patient. and PT time were in normal range. She was followed up for 9 days, and then discharged with the treatment of warfarin $5 \mathrm{mg}$ per day and metoprolol $25 \mathrm{mg}$ per day. The baby was stable in the neonate unite, and discharged with the mother.

\section{Discussion}

AMI may be observed in all trimesters of the pregnancy, but is more common in the third trimester and in the pregnant woman older than 33 years. Pregnancy MI is most common in the multigravida, and mostly localized at anterior wall. Twenty-nine percent of the coronary angiography patients had normal coronary arteries [4]. Atherosclerosis is the most common etiology of MI in the pregnancy, and observed in less than the half of the patients who had undergone coronary anatomy imaging [3]. According to the coronary angiography, our patient had a distal obstruction in PL branch of RCA. The other possible etiologies include thrombosis, coronary artery spasm, coronary artery dissection, Kawasaki disease, collagen vascular diseases, cocaine use, aortic and mitral prosthetic valve thrombosis and pheochromocytoma [5]. A study showed that $58 \%$ of the pregnant MI patients had cardiac risk factors. Smoking (20\%) and hypertension (25\%) are the most common risk factors, and the prevalence of diabetes mellitus (gestational or pregestational) is $3-5 \%$. The prevalence of other risk factors including hypercholesterolemia, hyperlipidemia and obesity is less than 5\% [1]. In our case, the etiology was identified as mitral prosthetic valve thrombosis which is an identified risk factor for MI during pregnancy. Therefore, oral anticoagulant was added to the treatment. Lower dose of aspirin can be used safely for MI during pregnancy [6]. There are no adequate data associated with abciximab and ticlopi- 
dine. ADP inhibitors cause platelet dysfunction in the fetus, and increase the risk of neonatal intracranial hemorrhage during vaginal delivery [7]. ST segment elevation MI is more common during pregnancy, but non-ST segment elevated MI was observed in only one case [8]. Our case was ST segment elevation inferior MI.

In conclusion, AMI prevalence is rare during pregnancy, but it is a serious life-threatening condition for the mother and the baby, therefore it should be noticed in the early period at the emergency department, and optimal treatment choices should be preferred for the mother and baby health.

\section{Conflicts of Interest}

We declared that we have no commercial, financial, and other relationships in any way related to the subject of this article all that might create any potential conflicts of interest.

\section{Funding Support}

None.

\section{References}

1. Hankins GD, Wendel GD, Jr., Leveno KJ, Stoneham J. Myocardial infarction during pregnancy: a review. Obstet Gynecol. 1985;65(1):139-146.
2. Badui E, Enciso R. Acute myocardial infarction during pregnancy and puerperium: a review. Angiology. 1996;47(8):739-756.

3. Roth A, Elkayam U. Acute myocardial infarction associated with pregnancy. Ann Intern Med. 1996;125(9):751762.

4. Maekawa K, Ohnishi H, Hirase T, Yamada T, Matsuo T. Acute myocardial infarction during pregnancy caused by coronary artery spasm. J Intern Med. 1994;235(5):489492.

5. Iadanza A, Del Pasqua A, Barbati R, Carrera A, Gentilini R, Favilli R, Pierli C. Acute ST elevation myocardial infarction in pregnancy due to coronary vasospasm: a case report and review of literature. Int $\mathrm{J}$ Cardiol. 2007;115(1):81-85.

6. Schomig A, Neumann FJ, Walter H, Schuhlen H, Hadamitzky M, Zitzmann-Roth EM, Dirschinger J, et al. Coronary stent placement in patients with acute myocardial infarction: comparison of clinical and angiographic outcome after randomization to antiplatelet or anticoagulant therapy. J Am Coll Cardiol. 1997;29(1):28-34.

7. Valcamonico A, Foschini M, Soregaroli M, Tarantini M, Frusca T. Low dose aspirin in pregnancy: a clinical and biochemical study of effects on the newborn. J Perinat Med. 1993;21(3):235-240.

8. G OSN, Garcia Martul M, Santana Cabrera L, Eugenio Robaina P, Hernandez Medina E, Sanchez Palacios M. [Acute coronary syndrome without ST elevation during pregnancy. A case report]. Med Intensiva. 2006;30(4):180182. 